\title{
ALGUNAS REFLEXIONES SOBRE LA DOCTRINA PLATÓNICA DE LOS PREÁMBULOS DE LAS LEYES*
}

\section{Eduardo García Máynez}

Instituto de Investigaciones Filosóficas Universidad Nacional autónoma de México

Después de ejercer sobre mí una amable coerción, el Sr. Dr. León Olivé logró al fín convencerme de que, pese al mal estado de mi salud - producto, en buena parte, de mis años- no debía negarme a presentar algún trabajo dentro de la serie de conferencias organizada por nuestro Director con motivo de la inauguración del nuevo edificio del Instituto de Investigaciones Filosóficas. Argumenté que no tenía escrito ningún texto que pudiera servir decorosamente al mencionado propósito, pero el Dr. Olivé me salió al paso diciéndome que no era necesario que redactase un estudio extenso, especialmente preparado para la mencionada celebración. "Puede Ud. -añadió- leer y comentar brevemente algunas páginas del tercer tomo de su obra Teorías sobre la justicia en los diálogos de Platón, inédita todavía, las que a su juicio ofrezcan mayor interés." Esta facilidad venció mi resistencia $\mathrm{y}$, después de repasar en mi memoria diversos aspectos de la obra de la que acabo de hablar, decidí ofrecer a Uds. algunas reflexiones sobre la teoria platónica de los preámbulos de las leyes, la cual, desde un principio, despertó poderosamente mi atención, no sólo por lo que al exponerla sostiene el hijo de Aristón y Perictiona, sino por lo mucho que el estudio de la misma suele sugerir.

\section{EXPOSICIÓN DE La DOCTRINA PLATÓNICA DE LOS PREÁMBULOS}

Si las leyes -escribe Platón en el libro IV de su obra póstumano han de ser simples intimaciones despóticas, mandatos incondicionales a los que el legislador enlaza un castigo para el caso del incumplimiento, sino expresión de una exigencia justa, el $\nu \circ \mu \circ \theta \dot{\epsilon} \eta \bar{\varsigma}$ concienzudo deberá anteponer a cada una de sus prescripciones un

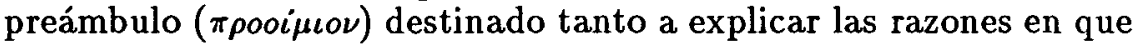

* Conferencia impartida dentro del ciclo "Los filósofos en el Colegio Nacional", organizado por el Instituto de Investigaciones Filosóficas. 
dicha exigencia se basa, como también, y sobre todo, a lograr que los destinatarios del precepto se convenzan de que lo legalmente prescrito no es un mandato arbitrario, sino una norma que merece la más respetuosa observancia.

Las que actualmente denominamos exposiciones de motivos no deben obedecer simplemente, a juicio del fundador de la Academia, a un propósito explicativo de las razones que indujeron al autor de la ley a elaborarla, ya que, si ésta ha de ser eficaz, la mejor manera de darle eficacia es persuadir a sus destinatarios de que tienen el deber de acatarla, no por miedo a la imposición coactiva, sino espontáneamente, por estar convencidos de que lo que ordena es intrinsecamente justo.

Sir Ernest Barker asevera - pensamos que con razón- que los preámbulos cuyo empleo Platón recomienda pueden ser vistos como un corolario del principio del autodominio que inspira los argumentos de las Leyes. Es verdad que toda ley auténtica es un mandato racional, "pero como la razón es soberana, la ley debe asumir la forma de un mandato igualmente soberano". La disposición normativa, como decimos hoy, es la parte de la norma por la cual "la perfecta virtud del autodominio es realizada" y el autodominio es "una armonía entre la razón y los apetitos". "Si planteamos la cuestión de esta guisa - prosigue el autor británico- resulta claro que la finalidad de los preámbulos platónicos es establecer dicha armonia, añadiendo la persuasión al mandato para que el apetito coincida con la razón."

Barker asevera que la combinación del preámbulo persuasivo y el imperativo legal "prepara el camino" para el esquema de gobierno que Platón preconiza. Tal combinación encuentra su "postulado político" en la constitución mixta, "que enlaza al principio democrático de la libertad el principio monárquico del orden". Resulta muy fácil entender el pensamiento del filósofo ateniense si concebimos sus preámbulos como "el puente" que permite pasar del régimen del filósofo experto al imperio de la ley. Los preámbulos expresan los principios que servirían de inspiración al gobernante ideal a quien las normas legales no le hacen falta; y estas últimas pueden concebirse como "la detallada aplicación" de los principios que el regente perfecto sin duda formularía. De acuerdo con esta teoría, la finalidad de los preámbulos resulta más importante aún que los preceptos que tienden a realizar los propósitos del autor de la ley, porque aquéllos contienen los principios en que la legislación se inspira, y éstos son el medio destinado a hacer posible tal realización.

Para explicar a Clinias y a Megilio la utilidad de los proemios, el ateniense se vale de un atinado parangón: 
"Bien sabéis - les dice- que en nuestras ciudades tenemos dos especies de médicos: una es la de los que curan a hombres libres; otra, la de los médicos de esclavos. Los primeros, después de enseñar a los últimos los rudimentos de su arte, los ponen a su servicio con el carácter de ayudantes. Estos aprendices de medicina son, por regla general, los que atienden a los siervos que han perdido la salud. Pero entre ellos y sus maestros existe una diferencia tan notoria como explicable, no sólo en lo que a su saber concierne, sino, sobre todo, en lo que atañe a la forma en que unos y otros tratan a sus pacientes. Los que cuidan a los esclavos suelen ser esclavos también, y nunca se toman la molestia de entrar en detalles con los enfermos sobre las dolencias que les aquejan, ni les permiten que hagan preguntas acerca de las mismas, sino que luego de recetarles cual si fuesen tiranos, con el mismo aire de suficiencia de los doctos, se alejan bruscamente para acudir a la cama de otro enfermo, descargando así a sus maestros de buena parte de los ciudadanos de su profesión. El auténtico terapeuta, en cambio, suele atender solamente a hombres libres como él; y, cuando llega el momento de formular un diagnóstico y aconsejar determinado régimen, siempre explica al paciente el origen y la naturaleza de su mal, procurando convencerlo, con razones de peso, de que debe tomar tales o cuales remedios. Nunca prescribe tiránicamente, como los aprendices, sino que antepone a sus prescripciones la persuasión. Puede, pues, hablarse de dos métodos de tratamiento, el doble, que es el que aplican los versados en el arte de la medicina, y el simple, único del que se sirven los médicos de esclavos."

La distinción entre los que podrían llamarse procedimiento despótico y procedimiento persuasivo es igualmente aplicable, según el ateniense, a la actividad legislativa. Lo dicho puede entenderse fácilmente, a juicio de Platón, con ayuda de un ejemplo, el de las leyes

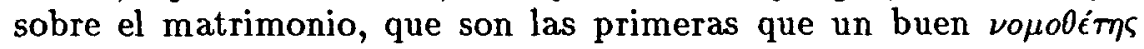
debe dictar.

El método simple, en el caso, probablemente consistiría en emitir el precepto siguiente:

"Casarse es obligatorio entre los treinta y los treinta y cinco años de edad; los castigos para el infractor serán la multa y la degradación civil (atimia): multa de tal o cual monto y atimía de tal o cual especie."

Esta es la versión simple de la norma; el proemio de la última, de acuerdo con el ateniense, rezaría así:

"Casarse es obligatorio entre los treinta y los treinta y cinco años de edad, considerando que el linaje humano, por don de la naturaleza, participa en cierto modo de la inmortalidad, a la cual todo 
hombre aspira de manera innata y en todos los respectos. La ambición de adquirir gloria y de no yacer, después de muerto, en una tumba anónima, da expresión a tal deseo. El género humano tiene una afinidad natural con el conjunto del tiempo, al que acompaña y acompañará siempre a través de su infinitud; aquél no morirá nunca, porque deja tras de sí a los hijos de los hijos. Por ser uno e idéntico a través de las generaciones participa de la inmortalidad. Privarse en forma voluntaria de este privilegio es acto que la piedad jamás permite; y se priva deliberadamente de él quien renuncia a tener mujer y descendientes. Si uno cumple con lo prescrito, no sufrirá ningún castigo; pero si desobedece y llega a los treinta y cinco años sin haber contraído matrimonio, anualmente deberá pagar una multa, para que no crea que la soltería le producirá comodidades y ganancias y, además, para que se vea privado de los honores que en la polis los más jóvenes tributan a los de mayor edad cuando la ocasión de hacerlo llega" (721a-721b).

Citaré un segundo ejemplo, el del preámbulo que, de acuerdo con el ateniense, habrá que anteponer a las leyes que castigan el robo de cosas sagradas. El pasaje a que me refiero dice así:

"Antes de cada una de las normas sobre estas materias habrá que colocar un corto preámbulo que sería como una plática o exhortación por medio de las cuales, dirigiéndonos a aquel a quien el deseo de robar algún objeto sagrado excita durante el día y despierta por las noches, le diríamos:

"Hombre extraño, no es humano ni divino el mal que ahora te mueve, induciéndote a perpetrar un robo sacrílego; es un furioso aguijón nacido en ti a consecuencia de antiguos crímenes no expiados por sus autores, funesto impulso contra el cual es necesario que luches con todas tus fuerzas; aprende de mí qué precauciones has de tomar para vencerlo. Cuando te asalte alguno de esos pensamientos, ve a someterte a los ritos purificatorios; acude como suplicante a los santuarios de los dioses que conjuran los maleficios; busca la compañía de aquellos que en tu comunidad tienen fama de virtuosos; escucha lo que otros dicen y trata también de decirte a ti mismo que todo hombre debe honrar lo que es bello y lo que es justo; huye, por último, de la compañía de los perversos, sin volver nunca la mirada. $\mathrm{Si}$, haciendo estás cosas, tu mal cede, enhorabuena; pero si no, juzga a la muerte como lo más hermoso y libérate de la vida" (Libro IX, 854a-854c).

"A nosotros, Megilio y Clinias - declara el ateniense- corresponde juzgar, tomando en cuenta los modelos anteriores, si al legislar vale más que optemos por el que hemos llamado método doble, exponiendo con la mayor claridad posible los motivos de la ley, o 
si hemos de servirnos del método simple y más corto, limitándonos sólo a la intimación."

"El lacedemonio se inclina siempre a lạ brevedad - contesta Megilio-; yo preferiría, empero, la redacción más extensa, y lo mismo haría respecto de cualquier otra ley. Pero es preciso que escuchemos el parecer de nuestro amigo, tanto más cuanto que las normas de que estamos hablando tendrían que ser aplicadas en su patria."

Clinias afirma que su opinión es la misma, y el ateniense sostiene que es una puerilidad preocuparse por la mayor o menor longitud de un razonamiento, pues lo que importa no es lo corto ni lo largo, sino lo mejor.

El parangón con las dos especies de médicos parece al de Atenas enteramente justo. En materia de legislación, sin embargo, ningún legislador ha aprovechado la enseñanza que de aquel paralelo puede obtenerse. Los encargados de la actividad legislativa pocas veces se percatan de que disponen de dos medios para dar aplicación a sus prescripciones: uno es la fuerza; el otro, la persuasión. Hablando de una manera general, debe tomarse en cuenta que allí donde la voz humana interviene suele haber preludios destinados a preparar lo que ha de seguir. Esto es usual en todo género de música, pero nadie ha pensado aún en hacer lo mismo con las normas legales; nadie les ha puesto proemios, como si las últimas, por su naturaleza, no debieran tenerlos.

Volviendo a la distinción entre leyes dobles y leyes simples, que pronto habrá de abandonar, por ser terminológicamente incorrecta, Platón, por boca del ateniense, expresa lo que sigue:

"Las que hace un momento nos pareció que eran leyes dobles, como las llamamos, no son realmente dobles, sino dos cosas diversas: una ley y el preámbulo o preludio de la misma; y el mandato que motejamos de tiránico, comparándolo con las prescripciones de los médicos de esclavos que ejercen la medicina, era la ley pura y simple. En cambio, lo que la precede y Megilio calificó de persuasión, es realmente tal, y tiene la misma función del exordio de un discurso. Que aquel a quien el legislador se dirige reciba el precepto con benevolencia y, gracias a su buena disposición, acepte más dócilmente el mandato, es decir, la ley, es la finalidad que explica todo lo que el autor aduce con el propósito de persuadir; por ello, en su opinión, el nombre que le corresponde es el de preámbulo, y no el de texto legal" (722-723). En otras palabras: los calificativos "doble" y "simple" convienen a dos distintos métodos de que el legislador puede servirse al realizar su función específica, no a dos diferentes clases de leyes. 
No hay por qué recordar a un auditorio tan distinguido como el que forman los juristas y abogados que me escuchan, las finalidades que de acuerdo con las doctrinas más recientes, pueden atribuirse a las actualmente llamadas exposiciones de motivos. El propósito de esta conferencia no es histórico; lo que me interesa es solamente poner énfasis en la utilidad que Platón reconoce a los preámbulos de las leyes y, de manera muy especial, en la convicción que el filósofo de la Academia tiene de que el legislador que trata de convencer a los destinatarios de la norma de que lo prescrito por ésta es una exigencia justa, constituye el medio más idóneo para lograr que los preceptos legales sean espontáneamente acatados, lo que al propio tiempo hace que en el ánimo del sujeto obligado el temor a las sanciones pase a ocupar un segundo término.

Esta reflexión me induce a esforzarme para dar respuesta a dos preguntas:

1) ¿Significa lo anteriormente expuesto que el propósito principal del legislador partidario de los proemios persuasivos es conseguir que los destinatarios del imperativo legal lo cumplan de manera espontánea, lo que da a sus mandatos el carácter de normas morales, más que el de intimaciones, a las que siempre acompaña la posibilidad de la imposición coactiva?

2) Se ha dicho, y yo lo he afirmado varias veces en mis libros, que uno de los rasgos que permiten distinguir al derecho de la moral es la incoercibilidad de ésta y la coercibilidad de aquél. Si ello es cierto (y de aquí proviene mi segunda pregunta), ¿vamos a sostener que la doctrina platónica de los preámbulos persuasivos tiende a desdibujar uno de los grandes criterios distintivos de las legislaciones ética y jurídica?

No lo creo, porque en todo derecho auténtico deben coincidir los atributos de la vigencia, la eficacia y la justicia, coincidencia que, por otra parte, condiciona la estructura ontológica de lo jurídico. Si esto es así, no podrá interpretarse la antítesis incoercibilidad de la moral/coercibilidad del derecho como incompatibilidad de las mencionadas características, sino como expresión de dos atributos que, lejos de excluirse, respecto de la conducta del destinatario de una ley, no son únicamente compatibles, sino que, al enlazarse entre sí, aseguran de la mejor manera la eficacia del precepto, porque la obediencia que dimana de la persuasión siempre será más valiosa que la impuesta por medio de la fuerza. 